\title{
Infrared examination of a special high reflecting coating for energy conservation
}

by Imre Dr. Benkö

\begin{abstract}
Faculty of Mechanical Engineering, Budapest University of Technology and Economics H-1112 Budapest, Cirmos u. 1. HUNGARY, ibenko@freestart.huibenko@freestart.hu
\end{abstract}

\begin{abstract}
The paper reports about infrared thermogrammetric (TGM) measurements made using a comparative technique for obtaining data for total and band emissivity of several specimens of different materials (metal, asphalt shingles, sealed and unglazed tile and felt etc.) covered by selective sun reflecting coating (SRC). The main aim of the work was to measure different low emissivity, sun reflecting coatings with a view to seeing whether the predicted results could be obtained.

The method used in the present study was of the 'direct comparative' type in which the intensity of radiation received by an infrared(IR) imaging equipment from the sun heated speciment was used to determine the normal band emissivity. The half of each specimen was coated by different SRC-coatings and the other half was uncoated. The emissivity was measured by a special method in two steps.In thermal equilibrium state the process took a few seconds and the video recording of the infrared measurements was subsequently evaluated with computerised analysis.

Directional measurements made at various fixed temperature levels showed little variation with angle of view, which indicated that the coating was a diffuse emitter. The direct sunshine was measured by a total radiation fluxmeter(see in the middle of Fig. 3). Using the emissivity of different materials a lot of diagrams was calculated for the equilibrium temperature ( $\left.t_{w e}\right)$ and 'heat gain' of the surface of wall structures in function of different parameters (intensity of direct sunshine, environmental temperature, coefficient of heat transfer, thermal resistance of wall structure,etc).
\end{abstract}

Keywords: Buildings, infrared imagery, low emissivity coatings, sunray radiation, energy conservation.

\section{Introduction}

Sun reflecting coating materials are used in ambient temperature applications (under $80{ }^{\circ} \mathrm{C}$ ) such as walls, roofs, heat shields, etc. where thermal radiation is a dominant mechanism of heat transfer. Thus there is a real need for data concerning the radiative properties of such materials.

The determination of the emissivity of coating materials is not straightforward mater. Severe practical difficulties arise in conection with the measurement of test specimen surface temperature using thermocouples embedded just below the surface. It is extremely difficult to achieve uniformity of temperature over the surface of a coated specimen operating at sunshine and it is probably for this reason that the calorimetric method of emissivity measurement has not found favor in the case of such materials and attention has instead been concentrated on radiometric techniques as IR-imagery,too.But in the case of practical approach, the use of IR-imagery gives a direct temperature difference between the coated and uncoated surfaces resulting a lower emissivity of the coating.

\section{Method of examination}

The measuring method consists of two successive steps. In the first step IR-imaging equipment, which viewed the speciment at right angle to the surface of the sample, received both the radiation emitted by the speciment and the sun radiation reflected from it. In the second step, after geting to the thermal steady state, shielded the sample from the sunshine, the IR-imaging equipment received only the radiation emitted by the nonuniform heated coated and uncoated sides of the specimen (that is the 'own radiation').

The special feature of the arrangement used in this case was a heat shield mounted on rotating arm. The shield consisted of a plate backed by insulating material. The shield was designed to fit over the surface of the specimen without touching it, held in position by a spring

The arrangement was designed so that when the specimen reached thermal equilibrium on the sunshine, the shield could then be quickly swung on the rotating arm, thus shielding the specimen from the sunshine and allowing only the own radiant an convective heat transfer to take place.Measurement was terminated after about 4 to 6 seconds. 
In the case of each measurements it was possible to vary the angle of view of the measuring equipment with respect to the normal to the surface of the speciment.(see Fig. 3). A well defined distribution of emissivity as a function of the quality of the specimen has been also presented for the coated and uncoated surfaces (see Figs. 5 and 6.). The average value of the emissivity for these surfaces can be calculated by histographycal method .

\section{Theoretical basis of the direct comparative methode}

The IR-radiation of different samples was examined under practical conditions, in direct sunshine. The half of the each sample was coated by selective coating and the other half was uncoated (Fig. 4). Infrared radiation emitted by the surfaces was measured by AGEMA thermal imaging eqipment with a special method.

As indicated before, the arrangement for the 'direct' method of emissivity measurement consists of a relatively small heated specimen having a surface temperature $T_{w}$ within a large environment which is at uniform temperature $T_{e}$. The specimen is assumed to be opaque to thermal radiation.

The sunshine radiation views a given target area on the specimen surface in the normal direction or at some angle $\theta$ to the normal. In the second step of the examination, the solar radiation absorbed by the specimen is transferred to the environment by emission and convective heat transfer. Thus

$$
q_{s}^{\bullet}(\theta) \cdot \varepsilon(\theta, T)=\varepsilon(\theta, T) \cdot \sigma \cdot\left(T_{w}^{4}-T_{c}^{4}\right)+2 \cdot \alpha(T) \cdot\left(T_{w}-T_{c}\right)
$$

Here $\sigma$ is the Stefan-Boltzmann constant, $\alpha$ is the coefficient of heat transfer in the heated specimen surface and $q^{\circ}$ s intensity of direct sunshie radiation in direction $\theta$.

From equation (1) it follows that

$$
\varepsilon(\theta, T)=2 \cdot \alpha(T) \cdot\left(T_{w}-T_{c}\right) /\left[q_{s}^{\bullet}(\theta)+\sigma \cdot\left(T c^{4}-T_{w}^{4}\right)\right]
$$
emissivity

Noting that according to Kirchhoff's Low applied to total values of absorbtivity a $\theta, T$ ) and

$$
a(\theta, T)=\varepsilon(\theta, T) .
$$

\section{Comparison of surfaces with different emissivities}

The surface emissivity of the coating was compared with that of specimen material. In Fig.5 and Fig. 6 on the thermogram are two quadrangles marked for which temperature distribution was computed. The temperature difference between the area coated with SRC-coating and the uncoated surface shows that the SRC-coating directly decreases the IR-emissivity of the material. Numerical values for the temperature represent the so called'effective black body temperature' (at thermal imaging eqipment's $\varepsilon=1$ ).

Equation between temperature and emissivity ratios comes from the next equality

$$
\sigma \cdot T_{1}^{4} \cdot \varepsilon_{1}=\sigma \cdot T_{2}^{4} \cdot \varepsilon_{2}
$$

So from Equation 4, it follows that

$$
\varepsilon_{1 /} \varepsilon_{2}=\left(T_{2} / T_{1}\right)^{4}
$$

\section{Presentation of results}

The results are presented in the form of:

(a) A plot of spectral reflectivity of SRC-coating as a function of wavelength of the radiation (Fig.2).

(b) IR-thermograms (Fig.5 and Fig.6) and table (Table 2) of sample for presnting the thermal effects of different material / coating couples. 
(c) Four plots of equilibrium temperature and intensity of 'heat gain' of different wall structures versus emissivity of surfaces, intensity of direct sunshine, coefficient of heat transfer and environmental temperature.

\section{Applications in the thermotechnique of buildings}

The factors affecting the infrared radiation of building surfaces and low temperature industrial equipment have not been widely enough studied. As far as building construction is concerned, the infrared radiation emissivity of walls has been regarded as an unchangeable factor basically dependent upon the temperature and quality of their material.

The research was based on different elestometric roof coatings (e.g. SRC-coatings, commercialized on name 'ALUMA-CHRON' [10], which are available also in Hungary [11]. The special coating is liquid-applied and cures the surface. It is applied to forming single, tough, seem-free rubberized roof/wall membrane. From thermal point of view the coating is a double function membrane: it saves energy years-round, as it lowers interior temperatures in summer and its low emissivity slows heat loss in winter.

\section{ALUMA-CHRON's properties}

Materials of buildings have generaly good heat radiation properties, but from energy management and building physics point of view this fact is not always convenient. Some coating materials, e.g. ALUMA-CRON (further on: AL-CHR) have good properties : their emissivity is considerablyy lower that of the material onto which they are applied. This paper gives an account only for the infrared emissivity decreasing effect of SRC-coati

\section{Performance characteristics}

AL-CHR is an elastomeric roof/wall coating available in different colours. It is liquid-applied and it perfectly conforms to shapes. It is an economical, practical alternative to total roof replacement. This rubberized coating provides excellent resistance to both chemical and weather deterioration. Extensive elongation and nearly $100 \%$ recovery allows the coating to strech to meet changing weather requirements as the roof expands and contracts.

AL-CHR remains flexible. It will not become rigid, crack or peel even at temperatures of $-40{ }^{\circ} \mathrm{C}$ and it keeps in heat stability under $+82^{\circ} \mathrm{C}$.

\section{Basic uses of AL-CHR coating}

One-coat AL-CHR waterproofs, rustproofs, seal leaks, saves energy, deadens sound of metal roofs and stretches to accomodate all sudden temperature changes without breaking.

It restores and protects aged metal, asphalt shingles, sealed and unglazed tile and felt (with stabilized asphalt) roofs.

It can recoat vinyl, chlorinated rubber, and epoxy coatings. It was originally designed to fill the need for a coloured roof and tank membrane that could handle unusual contours and steep slopes. It proved so effective that it now is used to coat all types of roofs, tanks, silos, and stucco or masonry sidewall where appearance, wheather resistance and corrosion control are esential.

\section{Role of pigment in Sun's Rays utilization}

Coloured pigments in living cells trap light. Light and pigments are vital to important biological processes. There is an essential difference between chlorophyll molecules and the other pigments(e.g. in coat of animals): chlorophyll participates in photosyntesis as well as giving a green leaf its colour.

Visible light and the electromagnetic spectrum. We are constantly bathed by electromagnetic energy, from radio waves to infrared rays(heat), X-rays, and gamma rays. Each category has a range of energies measured in oscillating waves of specific lengths. Only the small portion of the entire electromagnetic spectrum with wavelengths in the range $380-750 \mathrm{~nm}$ is visible to us as white light that can be broken into coloured light, each colour with different wavelengths. The shorter the wavelength, the more energetic the wave, the longer the wavelength, the less energetic.

\subsection{Pigments and absorption s}


The colours we see in a given object depend on which wavelengths of light the pigments in that object absorb and which are reflected back to our because all wavelengths are reflected. Black pigment in a coat absorbs light throughout the whole colour spectrum and reflect nothing. Thus, it looks black to us. A leaf contains chlorophyll-'a', which absorbs most strongly around 450 and $670 \mathrm{~nm}$, and chlorophyll -'b' , which absorbs most strongly around 490 and $650 \mathrm{~nm}$; green light in the $500 \mathrm{~nm}$ range is reflected, and thus the leaf looks green. The peelings of fruit often contain carotenoids, which absorb, wavelengths from 400 to about wavelengths from 400 to about 550nm and reflect back red, yellow and orange light. Because a leaf often contains both kinds of chlorophill plus carotenoid, its pigments can absorb and use for photosynthesis most of the wavelengths of visible light that strike it. However plants, algae and other autrophs use less than one percent of the energy of sunlight in photosynthesis.

In the technics, the spectral reflectivity of a special (Al-CHR) coating in function of wavelength of the radiation (between $200-600 \mathrm{~nm}$ ) is approx. $r=0.5-0.7$ (see Fig. 2).

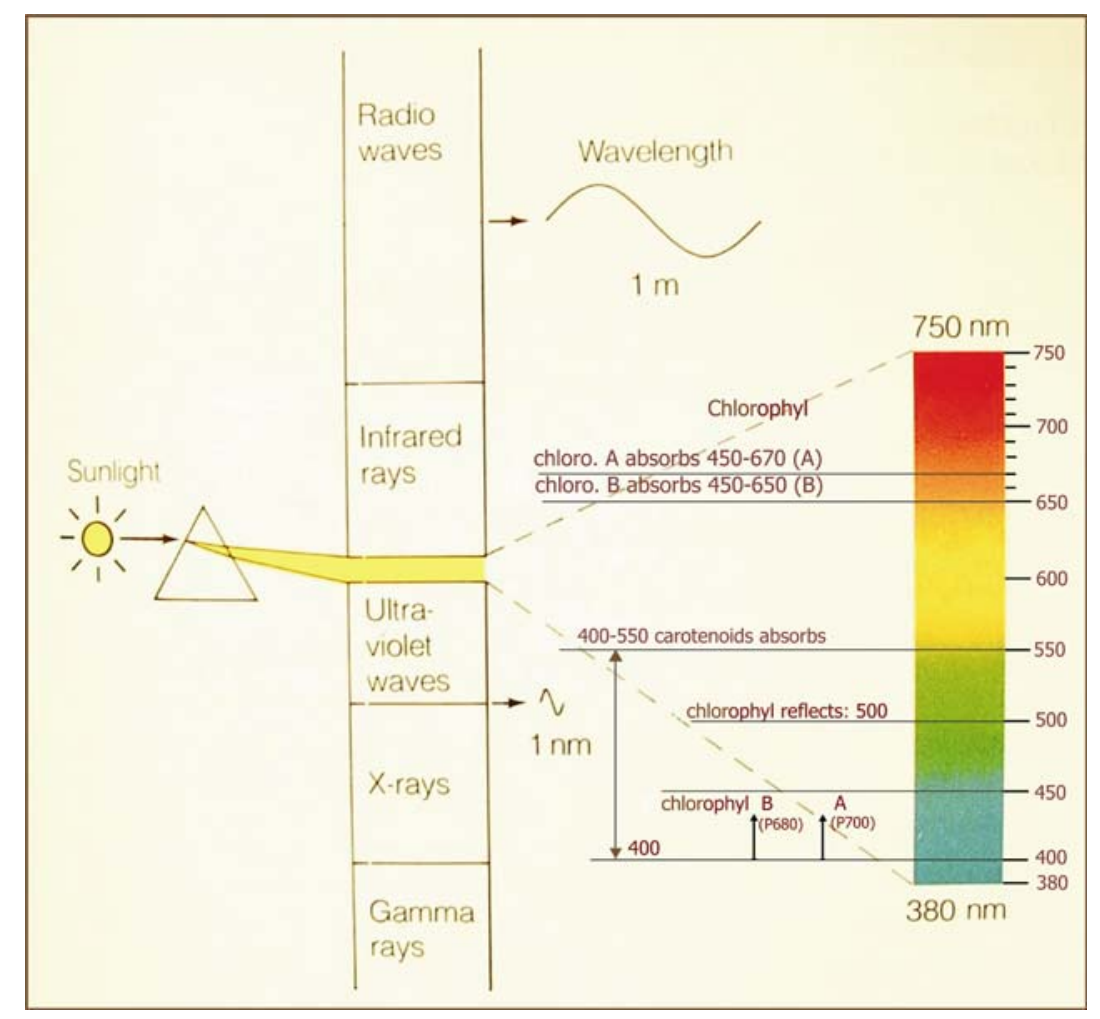

Fig. 1. Visible light and electromagnetic spectrum of pigments and absoption spectra 


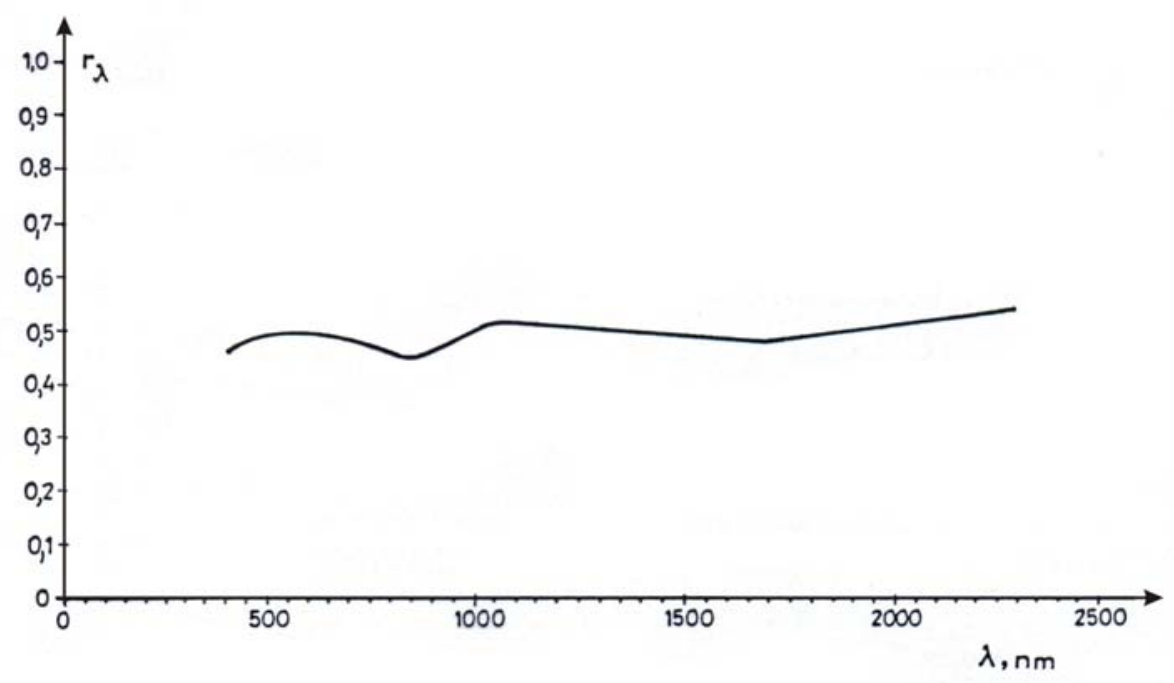

Fig. 2. Spectral values of the reflectivity of AL-CHR coating

Table 1. Technical data of AL-CHR (ALUMA-CHRON) elastomeric roof / wall coating

\begin{tabular}{|c|c|}
\hline Wet material & \\
\hline Metallic aluminium: & $6 \%$ \\
\hline Pigments: & $22 \%$ \\
\hline Non-volatile liquid elastomer: & $23 \%$ \\
\hline Dry to complete: & 3 days \\
\hline Solids by volume: & $48 \%$ \\
\hline Flashpoint of solvent: & $40^{\circ} \mathrm{C}$ \\
\hline Application temperature: & $5-49^{\circ} \mathrm{C}$ \\
\hline Wet film thickness & $\begin{array}{c}1 \text { liter/sq m, } \\
1 \mathrm{~mm}\end{array}$ \\
\hline Cured coating & \\
\hline $\begin{array}{l}\text { Elongation } \\
\text { at } 25^{\circ} \mathrm{C} \text { : } \\
\text { at } 0{ }^{\circ} \mathrm{C} \text { : }\end{array}$ & $\begin{array}{l}400 \% \\
200 \%\end{array}$ \\
\hline Return after elongation: & $>95 \%$ \\
\hline $\begin{array}{l}\text { U.V. reflection, white: } \\
\text { Light gray: } \\
\text { Colors: }\end{array}$ & $\begin{array}{c}90 \% \\
70 \% \\
<40 \%\end{array}$ \\
\hline U.V. resistance: & excellent \\
\hline $\begin{array}{l}\text { I.R. emissivity: } \\
\text { at low temperature, } 2 \div 6 \mu \mathrm{m} \text { : }\end{array}$ & $0.5 \div 0.7$ \\
\hline $\begin{array}{l}\text { I.R. reflectance: } \\
\text { at sunshine: } 0.4 \div 2.4 \mu \mathrm{m} \text { : }\end{array}$ & $0.45 \div 0.48$ \\
\hline Dry film thickness: & $\begin{array}{c}1 \text { liter/sq m: } 388 \\
\mu m\end{array}$ \\
\hline Dry film weight: 1 liter/sq.m: & $372 \mathrm{~g} / \mathrm{sq} . \mathrm{m}$ \\
\hline Re-coat interval: normally & $\begin{array}{l}10 \text { years or } \\
\text { more }\end{array}$ \\
\hline
\end{tabular}




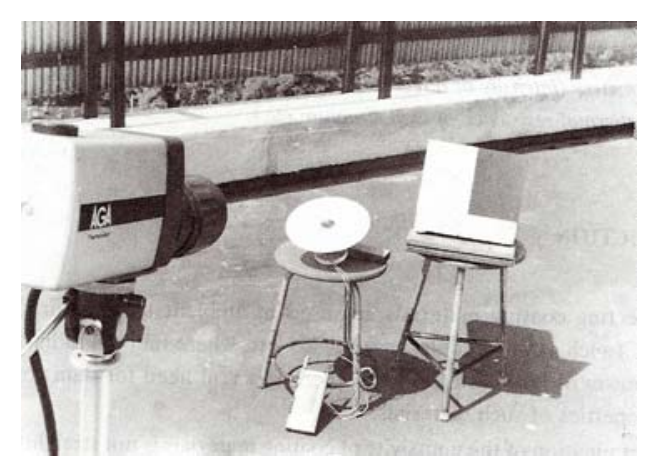

Fig. 3. Experimental arrangement for steady state and shielded measurements of emissivity

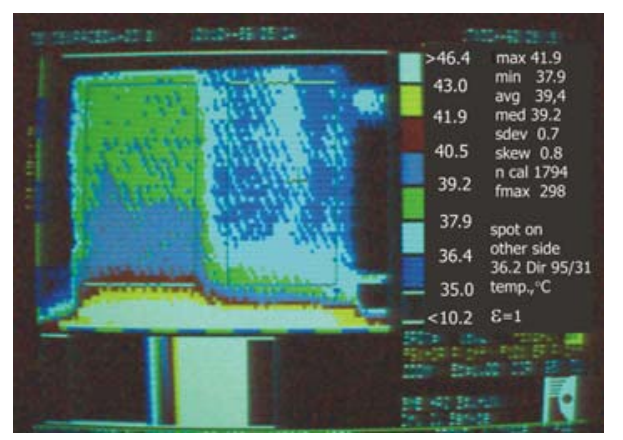

Fig. 5. IV-thermogram of a sample of Fig. 3. on direct sunshine.

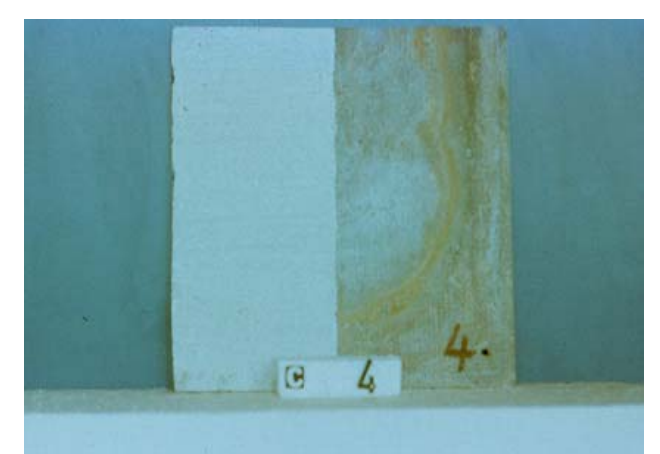

Fig. 4. A sample (Pace_04) of a slate roof

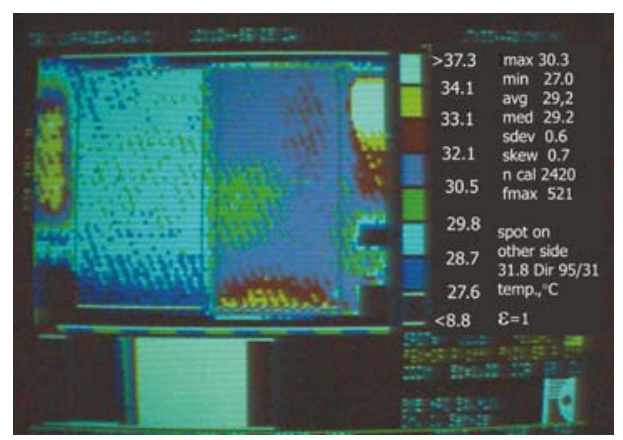

Fig. 6. IV-thermogram of a sample of Fig. 3. shielded from sunshine.

Table 2. Collection of histographical data of IR-thermograms (Fig.5 and Fig.6) for comparison of a specimen(Fig.4) on direct (s) sunshine and shielded (t) conditions: slate roof / SRC_04

\begin{tabular}{|l|l|l|}
\hline $\begin{array}{l}\text { On the right: } \\
\text { slate } \\
\text { roof }\end{array}$ & \multicolumn{2}{|c|}{ Temperature ${ }^{\circ} \mathrm{C}$} \\
\hline $\begin{array}{l}\text { On the left } \\
\text { (Pace_04) } \\
\text { temperature } \\
\text { values, }{ }^{\circ} \mathrm{C}\end{array}$ & $\begin{array}{l}\text { On } \\
\text { sunshine } \\
\text { (s) }\end{array}$ & $\begin{array}{l}\text { Shielded } \\
\text { (t) }\end{array}$ \\
\hline $\begin{array}{l}\text { Spot on the } \\
\text { other side }\end{array}$ & 36.2 & 31.8 \\
\hline \hline Dir x/y & $95 / 31$ & $95 / 31$ \\
\hline \hline max & 41.9 & 30.3 \\
\hline \hline min & 37.9 & 27.0 \\
\hline avg & 39.4 & 29.2 \\
\hline med & 39.2 & 29.2 \\
\hline sdev & 0.7 & 0.6 \\
\hline Skew & 0.8 & 0.7 \\
\hline \hline Ncal, pixel & 1794 & 2420 \\
\hline \hline Fmax, pixels & 248 & 521 \\
\hline
\end{tabular}




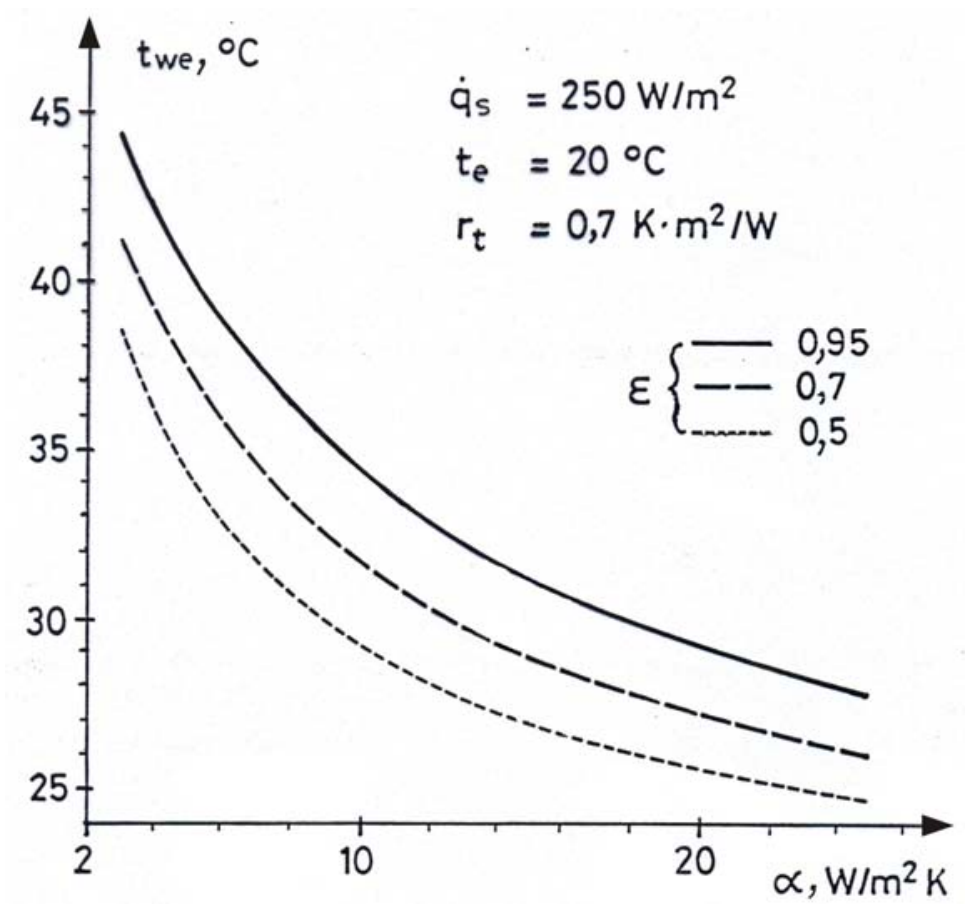

Fig. 7. Equilibrium temperatures of a wall structure ( $r_{t}$ denotes the thermal resistance of wall structure) against coefficient of heat transfer

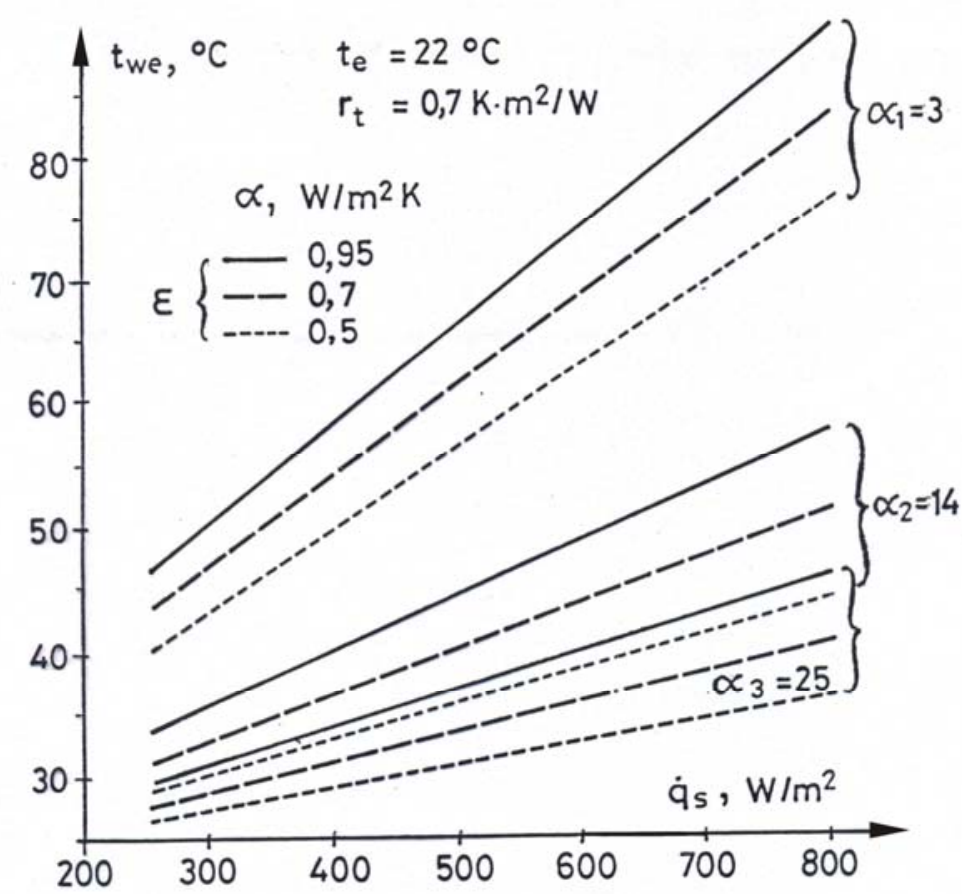

Fig. 8. Equilibrium temperatures of a wall structure $\left(r_{t}=0.7 \mathrm{~K} \cdot \mathrm{m}^{2} / \mathrm{W}\right)$ versus intensity of direct sunshine radiation 


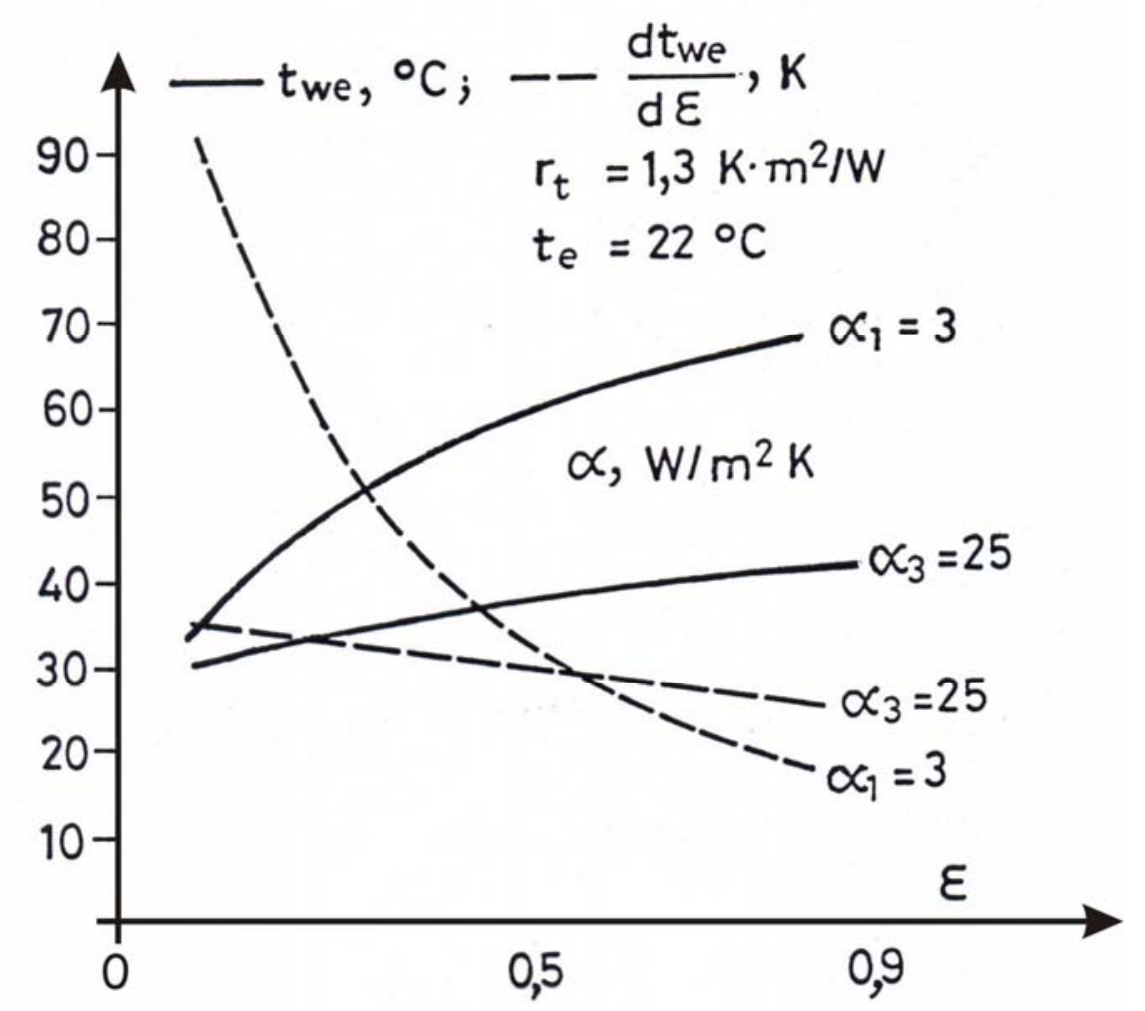

Fig. 9. Values and differential ratios of equilibrium temperatures of wall structure vs. emissivity

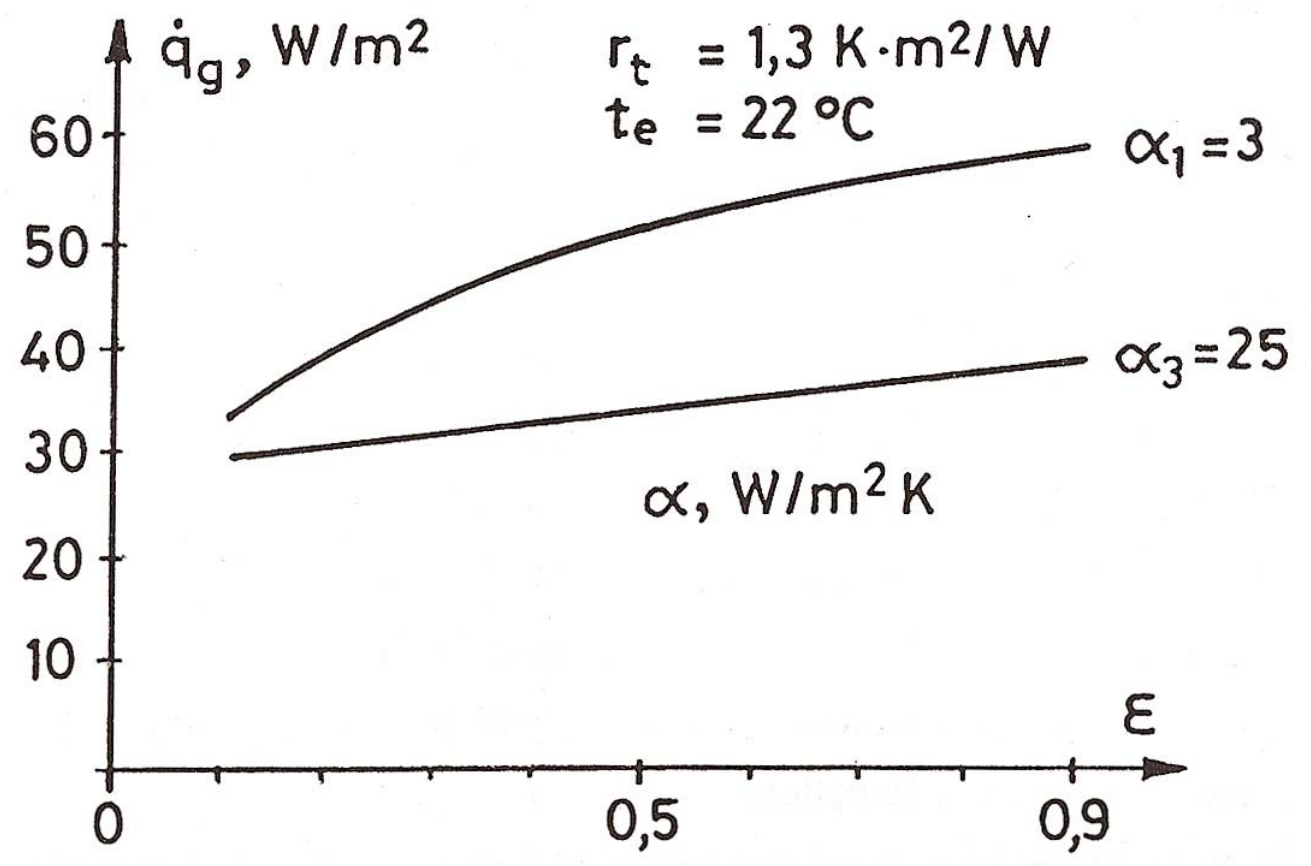

Fig. 10. Intensity of ' heat gain ' of wall structure vs. emissivity 


\section{REFERENCES}

[1] Benko \& L. I. Kiss, The struggle of mankind to ensure a comfortable thermal environment. The River Valley as a Focus of Interdisciplinary Research; Proceedings of the International Conference to Commemorate Maupertuis' Expedition to the River Tornio, Northern Finland, 1736-1737., Oulu, Finland, p. 8. 1977.

[2] Benko \& L. I. Kiss, Effects of isolation and integration on the development of systems Proceedings of the International Conference: The Archipelago as a Focus for Interdisciplinary Research. Turku, Finland (1978), Hamdan Foundation Pakistan, Karachi, pp. 49-68, 1981,

[3] I. Benko, Possibilities of utilising renewable energy sources, Periodica Polytechnica, Mech. Eng. Vol. 25, No. 1, pp. 67-86,.Budapest, Hungary, 1981,

[4] COEC, The Solar Handbook, Denver, Colorado, U.S.A., 1981.

[5] J. H. Postlethwait \& J. L. Hopson, The Nature of Life, McGraw-Hill, 1989.

[6] H. N. Rostvik, The Sunshine Revolution, SUNLAB Publ., Stavanger, Norway, 1992.

[7] I. Benko, Examination of low emissivity coatings by infrared imagery, Advanced Infrared Technology and Applications, Grafiche Troya Publ., pp. 185-197, Firenze, 1993,

[8] I. Benko, The role of exergy and entropy in thermal engineering applications, The $1^{\text {st }}$ International Exergy, Energy and Environment Symposium (IEEES-1), Izmir, Turkey, p. 81,. 2003,

[9] I. Benko, Thermal behaviour and entropy of living organisms through examples, Proceedings of the $2^{\text {nd }}$ WSEAS/IASME International Conference on Energy Planning, Energy Saving, Environmental Education (EPESE'08), Corfu, Greece, October 26-28, pp. 19-24,2008,

[10] Data Specs of PACE Products Internatioanl, Inc.

[11] MULTITREND Ltd., H-1031 Budapest, Zahony u. 13., Hungary 